\title{
Life Satisfaction and Resilience among Divorced Women in India
}

\author{
Gautami Kapila $^{1 *}$, Dr Arun Kumar ${ }^{2}$
}

\section{ABSTRACT}

Aim: The purpose of the study was to identify the level of Life Satisfaction and Resilience among the divorced women in India. Method: This study aims to identify the relationship between Life satisfaction and resilience. Standardized questionnaires (LIFE SATISFACTION SCALE \& CONNOR DAVIDSON RESILIENCE SCALE) were employed to measure Life satisfaction and Resilience, among 60 divorced women (Group1: women divorced for less than 5 years \& Group 2: women divorced for more than 5 years), all aged between 30-50 years. The results were analysed using T-test and Pearson r. The score were tabulated. Results: The statistical analysis suggested a positive correlation between Life satisfaction and Resilience. The results also indicated that there is no significant difference between the level of life satisfaction and resilience among the Group 1 and Group 2.

Keywords: Resilience, Life satisfaction

\section{Life Satisfaction}

Life Satisfaction is the way an individual assesses his or her life and how he or she feels about where it is heading on in their lives. It is a measure of prosperity and may be evaluated as far as inclination, satisfaction with relations with others and with attainment of objectives, thoughts toward oneself, and capacity to adapt to everyday life. It is having a great disposition of one's life in general as opposed to an evaluation of current sentiments. Life Satisfaction has been measured in connection to financial standing, measure of instruction, encounters, and habitation, and also numerous different themes. Life Satisfaction measures how individuals assess their life all in all as opposed to their current sentiments. It catches an intelligent evaluation of which life circumstances and conditions are vital for subjective prosperity.

\section{Reselience}

"Resilience basically expressed, is sure adjustment because of misfortune" (Waller, 2001). Resilience in brain science alludes to the thought of a singular's capacity to adapt to push and misfortune. This adapting may bring about the individual "bouncing back" to a past condition of ordinary working, or experience the presentation of misfortune to create a "steeling impact" and capacity better than anticipated. Resilience can demonstrate an ability to oppose a sharp decrease in working despite the fact that an individual briefly seems to deteriorate (Masten, 2009).

\footnotetext{
${ }^{1}$ MA, Clinical Psychology, Amity Institute of Behavioural Health and Allied Sciences, Uttar Pradesh, Noida

${ }^{2}$ Associate Professor, Clinical Psychology, Amity Institute of Behavioural Health and Allied Sciences, Uttar Pradesh, Noida use, distribution, and reproduction in any Medium, provided the original work is properly cited.
} 


\section{Divorce}

Divorce (or the dissolution of marriage) is the termination of a marital union, the cancelling and/or reorganizing of the legal duties and responsibilities of marriage, thus dissolving the bonds of matrimony between a married couple under the rule of law of the particular country and/or state.

The dissolution of a marriage is a lawful demonstration that may not generally harmonize with a couple's enthusiastic shredding. Divorce is regularly an excruciating procedure for all concerned. While it can take grown-ups time to recover mental balance, whether kids ever recuperate a stable point of view keeps on being discussed.

\section{REVIEW OF LITERATURE}

Garmezy (1973) was the first individual who published the first research discoveries on Resilience. In his exploration he utilized the study of disease transmission which is the investigation of who gets sick, who doesn't, and why, to reveal the dangers and the defensive variables which presently helps to characterize Resilience Garmezy\&Streitman (1974) then made instruments to take a gander at frameworks that help improvement of Resilience.

Werner (1971) was one of the early researchers to utilize the term Resilience in 1970s. She examined an accomplice of kids from Kauai.

Resilient youngsters and their families had qualities that made them not the same as non-strong kids and families.

Research on the relationship between life satisfaction and Resilience is steady. Fredrickson, et al. (2003) found that Resilience was associated to life satisfaction. Bailey \& Snyder (2007) examined on life satisfaction and discovering showed that life satisfaction was decidedly identified with trust, respect toward oneself, feasibility toward oneself, locus of control, and looking for social backing rust, respect toward oneself, reasonability toward oneself, locus of control, furthermore looking for social backing are defensive elements for resilience.

Ritu Rani and PunamMidha(2014), studied Does Resilience enhance Life satisfaction among Teenagers .

Perceptions of the Societal Image of Muslim Arab Divorced Men and Women in Israel , Rivkasavaya (2003), Discoveries demonstrate that, overall, the members see their general public as deriding separated ladies as awful folks and life partners more than separated men, that separated ladies see more prominent societal criticism than separated men, and that acclimation to separate was specifically identified with people's view of the societal picture of the separated individual they could call their own sex.

Psychological wellbeing of single women in relation to learned optimism, resilience and proactive coping, SangeetaTrama, et al (Punjabi University, Patiala, Punjab) the present study 
proposed to look at the positive connects of mental prosperity of single ladies which help them in recuperating from injury and anxiety. The results uncovered that strength, proactive and instrumental adapting were the significant determinants of general mental prosperity of single ladies.

\section{METHODOLOGY}

Aim:

The purpose of the study is to explore the level of resilience and life satisfaction among divorced women in India

\section{Objective:}

1. To check the relationship of resilience and life satisfaction among divorced women

2. To assess the level of resilience among divorced women

3. To investigate the level of life satisfaction among divorced women

\section{Hypotheses:}

- Resilience is positively correlated with life satisfaction.

- There will be significant difference between the level of life satisfaction among women divorced for less than 5years and women divorced for more than 5 years.

- There will be significant difference between the level of resilience among women divorced for less than 5years and women divorced for more than 5 years

\section{Sample and Its Selection:}

The sample consisted of 60 divorced women. They were equally divided in to two groups:

Group 1: Women divorced for less than 5 years

Group 2: Women divorced for more than 5 years.

They were all aged between $30-50$ years. They all belonged to upper and middle class status.

\section{INCLUSION CRITERIA:}

- Women divorced for more than 5 years

- Women divorced for less than 5 years

- Women from middle class and upper middle class

- Women aged 30 years to 50 years

\section{EXCLUSION CRITERIA:}

- Women whose divorce has not yet been granted or under process

- Women living separately but not granted divorce

- Women who have been remarried 


\section{Description of the Tools Employed}

The following tools were used to carry out the present study:

1) Personal details Data Sheet

2) Satisfaction with Life Scale

3) Connor Davidson Resilience Scale ( CD RISC-25 )

\section{Procedure}

A non-experimental, comparative (within group) design was used for the current study. Sample meeting the inclusion and exclusion criteria were selected from upper and middle class socio economic status. First the participants were made to fill an informed consent form for ethical considerations. Information was gathered from entire sample on a semi structured personal details data sheet and were then asked to complete the Satisfaction with Life Scale By Diener and the Connor Davidson Resilience Scale.

The raw scores were first compiled in tabular form manually and then statistically evaluated. The analyses included mean, standard deviation, Person's correlation and T-test for the purpose of testing hypothesis.

\section{RESULTS AND ANALYSIS}

Hypothesis 1: Resilience is positively correlated to Life satisfaction

Table 1: Correlation coefficients for Resilience and Life satisfaction among Divorced Women in India

\begin{tabular}{|l|l|l|}
\hline SCALES & THE RESILINCE & LIFE SATISFACTION \\
\hline The Resilience & 1 & .628 \\
\hline Life Satisfaction & .628 & 1 \\
\hline
\end{tabular}

**. Correlation is significant at the 0.01 level (2-tailed).

The result depicted in the table 1 is to be found that there is as positive correlation between Resilience and Life Satisfaction. The findings suggested that women who were satisfied with their lives, were also high on resilience

Hypothesis 2: There will be significant difference between the level of Life satisfaction among women divorced for less than 5years and women divorced for more than 5 years.

Table 2:Mean, Standard deviation, T, and p value for Life Satisfaction.

Group1: women divorced for less than 5 years

Group 2: women divorced for more than 5 years

\begin{tabular}{|l|l|l|l|l|l|}
\hline GROUPS & N & MEAN & SD & t & p \\
\cline { 1 - 4 } & 30 & 23.8333 & 8.04335 & -1.227 & .011 \\
\hline 2 & 30 & 26.0333 & 5.63538 & & \\
\hline
\end{tabular}

Note $-\mathrm{N}=60, d f=58 \mathrm{p}<0.05$ 
The result of the Table 2 shows that there is difference between the two groups for Life satisfaction, but not statically significant. The result does not appear to support the hypothesis that there will be significant difference between the level of life satisfaction women divorced for less than 5years and women divorced for more than 5 years. Overall itshows that, women, are satisfied with their life, irrespective of the years of divorce.

\section{Chart no 1}

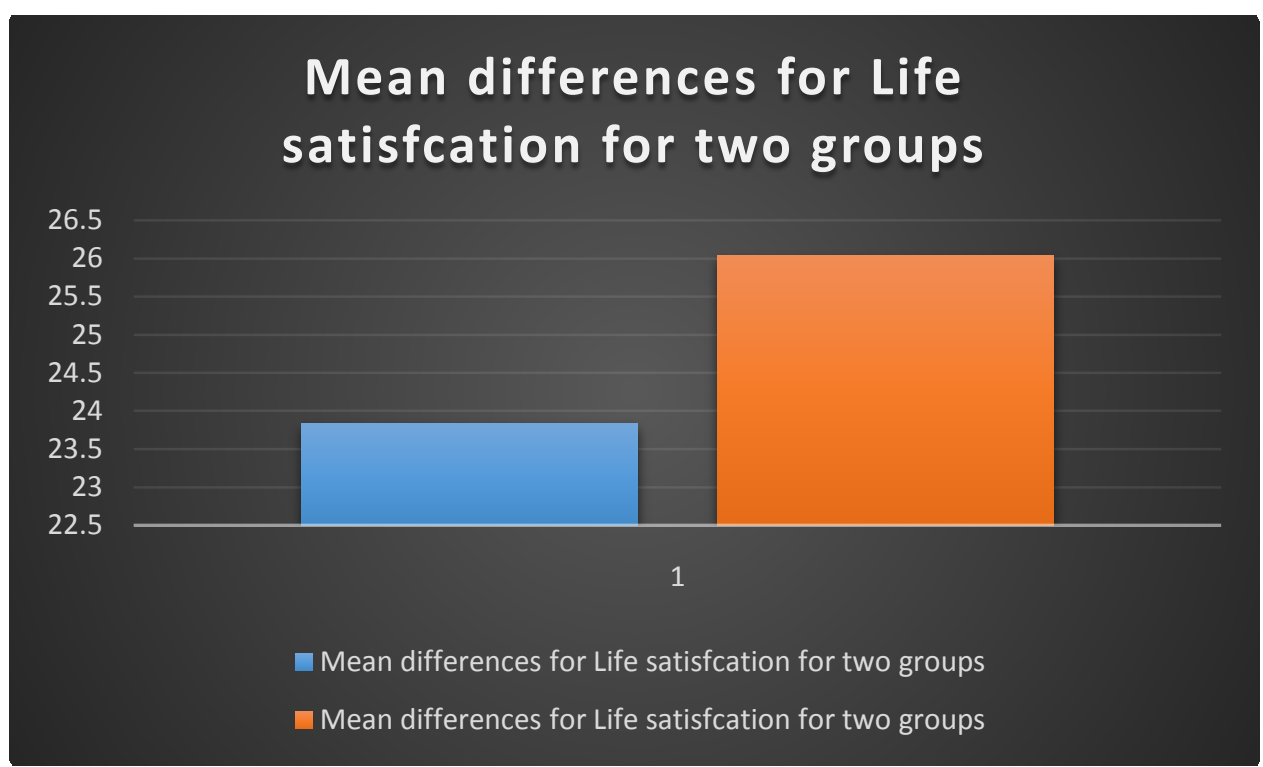

Hypothesis 3: There will be significant difference between the level of Resilience among women divorced for less than 5years and women divorced for more than 5 years.

Table 3:Mean, Standard deviation, T, and $p$ value for Resilience.

Group1: women divorced for less than 5 years

Group 2: women divorced for more than 5 years

\begin{tabular}{|l|l|l|l|l|l|}
\hline GROUPS & $\mathbf{N}$ & MEAN & SD & t & p \\
\cline { 1 - 4 } & 30 & 74.9667 & 20.15369 & .994 & .088 \\
\hline 2 & 30 & 70.2333 & 16.56894 & & \\
\hline
\end{tabular}

Note $-\mathrm{N}=60, d f=58, p>0.05$

The result of the Table 3 show that there is difference between the two groups for Resilience, but not statically significant. The result does not appear to support the hypothesis that there will be significant difference between the level of Resilience women divorced for less than 5years and women divorced for more than 5 years. Overall it shows that, on an average, women showed high resilience. 


\section{Chart No 2}

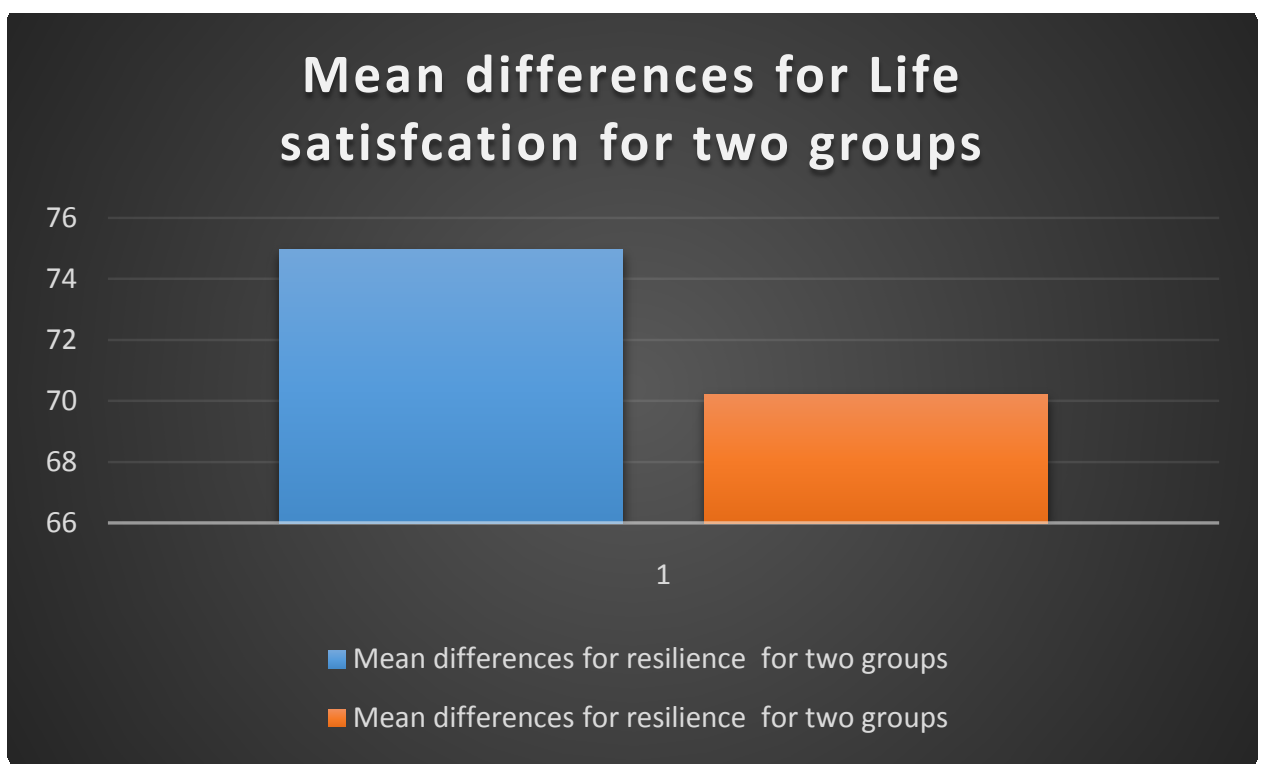

\section{DISCUSSION}

The purpose of the study was to explore the level of resilience and life satisfaction among divorced women in India. The idea of Resilience alludes to limit of individual to adapt well under affliction. Resilience is better seen as the opportunity and limit of individual to explore their approach to mental, social, and physical asset that may support their prosperity and limit independently and all in all experience importance full ways (Unger, 2008). Life satisfaction alludes to the individual's subjective, worldwide development of the emphatically of his/her life as entire or particular life area (Diener, Suh, Lacus \& smith, 1999).

A non-experimental, comparative (within group) design was used for the current study. Sample meeting the inclusion and exclusion criteria were selected from upper and middle class socio economic status. First the participants were made to fill an informed consent form for ethical considerations. Information was gathered from entire sample on a semi structured personal details data sheet and were then asked to complete the Satisfaction with Life Scale By Diener and the Connor Davidson Resilience Scale .The raw scores were first compiled in tabular form manually and then statistically evaluated. The analyses included mean, standard deviation, Person's correlation and T-test for the purpose of testing hypothesis.

The first hypothesis relating to the correlation of resilience and life satisfaction was upheld by the finding. In this path there was positive relationship between resilience and life satisfaction. Individual with high level of resilience adapt to life misfortune well and have a larger amount of life satisfaction. Resilience was decidedly connected to the life satisfaction. Resilient individual level of life satisfaction was higher than those of strong individual (Fredrickson, 2002). Bailey \& Snyder (2007) examined on life satisfaction and discovering showed that life satisfaction was decidedly identified with trust, respect toward oneself, feasibility toward oneself, locus of 
control, and looking for social backing rust, respect toward oneself, reasonability toward oneself, locus of control, furthermore looking for social backing are defensive elements for resilience. Subsequently, the present study guesses that there is a relationship between life satisfaction and resilience. Ritu Rani and PunamMidha(2014), further discovered that there is a strong positive correlation between resilience and life satisfaction.

Individuals who seed their existence with frequent moments of positive feelings expand their resilience against difficulties. Resilience notwithstanding misfortune could be a normal for somebody who is really fulfilled by his or her life. Researchers from the Universitat Autonoma de Barcelona found that individuals who are stronger are additionally more inclined to report high life satisfaction and control over feelings. As indicated, resilience is imperative for managing hardships, and can be found out and created. Elements that go into strength incorporate having the capacity to oversee driving forces and emotions, taking a gander at yourself decidedly, making reasonable arrangements and objectives and conveying and tackling issues.

The second hypothesis was that there will be significant difference between the level of Life satisfaction among women divorced for less than 5years and women divorced for more than 5 years. The findings does not show any significant difference in the level of Life satisfaction among the divorced women. Although there was a slight difference among the two groups for the level of life satisfaction, but not enough to be statistically significant. The p value was also less than 0.05 , indicating no statistically significant difference between the two conditions. The hypothesis cause of rejection can be chance error or sampling error. Although Group 2 (women divorced for more than 5 years) were more satisfied with the life than Group 1 (women divorced for less than 5 years), although the difference is not significant.

The third hypothesis was that there will be significant difference between the level of Resilience among women divorced for less than 5 years and women divorced for more than 5 years. The findings does not show any significant difference in the level of Resilience among the divorced women. Although there was a slight difference among the two groups for the level of life satisfaction, but not enough to be statistically significant. Also it was noted that Group 1 (women divorced for less than 5 years), were more resilient than Group 2 (women divorced for more than 5 years), although the difference is not significant. The hypothesis cause of rejection can be chance error or sampling error.

Following the hypothesis $2^{\text {nd }}$ and $3^{\text {rd }}$, we see that both the condition are not statistically significant, although the condition show a slight difference among themselves. The years since divorce did not made any difference. The participants were duly satisfied with their lives and were resilient, irrespective of the years since their divorce. Resilience includes keeping up adaptability and adjust in your life as you manage upsetting circumstances and traumatic occasions. Divorce is too complex a process to produce just winners and losers. People adjust in many different ways, and these patterns of adjusting change over time. The participants showed positive capacity to cope up with stress and catastrophe. It also suggested to indicate a 
characteristic of resistance to future negative events. Sangeeta Trama, et al (Punjabi University, Patiala, Punjab) proposed to look at the positive connects of mental prosperity of single ladies which help them in recuperating from injury and anxiety. The results uncovered that strength, proactive and instrumental adapting were the significant determinants of general mental prosperity of single ladies. While resilience, preventive, instrumental and enthusiastic adapting were critical in impacting mental trouble and Resilience and were relevant in clarifying mental prosperity of single women.75\% of the change in mental misery and $77 \%$ of the difference in mental prosperity was being clarified by the aforementioned variables. Subsequently, the results uncover the related pretended by the positive relates, particularly resilience and adapting (proactive, intelligent, help looking for, preventive, instrumental, passionate and avoidant adapting) in deciding mental prosperity of single ladies.

The investigation has clearly shown that the participant have used this experience to become to more strong and resilient. The participants are content with or accept or satisfied of one's wants and needs for one's life as a whole. The participants were able to make sensible arrangements and make moves to do them. A positive perspective of yourself and trust in your qualities and capacities, is what made them satisfied with life and resilient. Aptitudes in correspondence and critical thinking. The ability to oversee solid emotions and driving forces.

Hence the study concludes to say that the traumatic events like that of divorce, made the participants satisfied with their lives and consequently, more resilient, as a result of which they are able to have a positive image of themselves and are happier.

\section{CONCLUSION}

The purpose of the study was to explore the level of resilience and life satisfaction among divorced women. Statistical analysis indicated the following

1.Resilience is positively correlated to the life satisfaction.

2. The participants, who were satisfied with their life, also displayed high resilience.

3. Also, there was no significant difference among the level of life satisfaction and resilience between the two groups.

4. An interesting finding was that, the years since divorce, played no role. Irrespective of the years, the participants displayed approximately same level of life satisfaction and resilience.

Overall the results showed that resilience and life satisfaction are two phenomenon that are parallel.

\section{FUTURE DIRECTION}

The more research should be done in this context, as to validate the point that years since divorce makes no differences. Researching the progress of divorce and creating a valuation for the wellbeing of the individual after divorce, to change mentality and, inevitably, to bring about a significant improvement for individuals and the children, after divorce is crucial. 


\section{LIMITATIONS}

1. As the sample is taken mainly from urban areas \& from upper and middle class background, it cannot be generalised to all the people of the countries. Also the results cannot be applied to illiterate and non-working divorced women.

2. The researcher discovered few challenges in accumulation of the information that the majority of the individuals indicated non cooperative practices.

\section{REFERENCES}

Akbar, M., Akram, M., Ahmed, M., Shahbaz Hussain4, M., lals, V., \&Ijaz, S. (2014). â€ Relationship between Resilience and Life Satisfaction among Nomadic (mastes). International Journal of Innovation and Applied Studies.

Bailey, T., \&Synder, C. (2007). Satisfaction with life and hope: A look at age and marital status. The Psychological. The Psychological Record, 57, 233-240.

Diener, E., \&Diener, M. (1995). Cross-cultural correlates of life satisfaction and self-esteem. Journal Of Personality And Social Psychology, 68(4), 653-663. doi:10.1037/00223514.68.4.653

Fredrickson, B., Tugade, M., Waugh, C., \& Larkin, G. (2003). What good are positive emotions in crisis? A prospective study of resilience and emotions following the terrorist attacks on the United States on September 11th, 2001. Journal Of Personality \& Social Psychology, 84(2), 365-376. doi:10.1037//0022-3514.84.2.365

Garmezy, N. (1974). Children at Risk: The Search for the Antecedents of Schizophrenia. Part I. Conceptual Models and Research Methods. Schizophrenia Bulletin, 1(8), 14-90. doi:10.1093/schbul/1.8.14

http://www.apa.org,. (2015). The Road To Resilience. Retrieved 4 April 2015, from http://www.apa.org/helpcenter/road-resilience.aspx

Life satisfaction. (2001). In ), Encyclopedia of women and gender; sex similarties and differences and the impact of society on gender. San dieofo, CA.

LUTHAR, S., \& CICCHETTI, D. (2000). The construct of resilience: Implications for interventions and social policies. Develop. Psychopathol., 12(4), 857-885. doi:10.1017/s0954579400004156

Pavot, W., Diener, E., Colvin, C., \&Sandvik, E. (1991). Further Validation of the Satisfaction With Life Scale: Evidence for the Cross-Method Convergence of Well-Being Measures. Journal Of Personality Assessment, 57(1), 149-161. doi:10.1207/s15327752jpa5701_17

Psychologytoday.com,. (2015). Divorce | Psychology Today. Retrieved 4 April 2015, from http://www.psychologytoday.com/basics/divorce

Snyder, C., \& Lopez, S. (2007). Positive psychology. Thousand Oaks, Calif.: SAGE Publications.

Werner, E. (1993). Risk, resilience, and recovery: Perspectives from the Kauai Longitudinal Study. Develop. Psychopathol., 5(04), 503. doi:10.1017/s095457940000612x

Women's Web: For Women Who Do,. (2015). Life after divorce for women in India. Retrieved 4 April 2015, from http://www.womensweb.in/articles/after-indian-marriage-breaks-up/ 